\title{
Ileal Varices Treated with Balloon-Occluded Retrograde Transvenous Obliteration
}

\author{
Takahiro Sato ${ }^{\text {a, b }}$, Katsu Yamazaki ${ }^{a}$, Jouji Toyota ${ }^{a}$, Yoshiyasu Karino ${ }^{\text {a }}$ \\ Takumi Ohmura ${ }^{a}$, Jun Akaike
}

\begin{abstract}
A 55-year-old man with hepatitis B virus antigen-positive liver cirrhosis was admitted to our hospital with anal bleeding. Colonoscopy revealed blood retention in the entire colon, but no bleeding lesion was found. Computed tomography images showed that vessels in the ileum were connected to the right testicular vein, and we suspected ileal varices to be the most probable cause of bleeding. We immediately performed double balloon enteroscopy, but failed to find any site of bleeding owing to the difficulty of fiberscope insertion with sever adhesion. Using a balloon catheter during retrograde transvenous venography, we found ileal varices communicating with the right testicular vein (efferent vein) with the superior mesenteric vein branch as the afferent vein of these varices. We performed balloon occluded retrograde transvenous obliteration by way of the efferent vein of the varices and have detected no further bleeding in this patient one year after treatment.
\end{abstract}

Keywords: Balloon-occluded retrograde transvenous obliteration; Ectopic varices; Ileal varices; Interventional radiology; Portal hypertension

\section{Introduction}

Ectopic varices that are not esophagogastric are located predominantly in the duodenum, jejunum, ileum, colon, rectum, or enterostomy stoma [1]. Bleeding from ileal varices, which is rare in patients with portal hypertension, is generally massive and life threatening. Diagnosis of ruptured ileal varices and control of bleeding are difficult.

Manuscript accepted for publication April 16, 2009

${ }^{a}$ Department of Gastroenterology, Sapporo Kosei General Hospital, Kita 3 Higashi 8, Chuo-ku, Sapporo 060-0033, Japan.

bCorresponding author: taka.sato@ja-hokkaidoukouseiren.or.jp

doi:10.4021/gr2009.04.1286
Endoscopic injection sclerotherapy (EIS) is a standard procedure for treatment of esophageal varices [2]. More recently, endoscopic variceal ligation (EVL) has been applied widely in the treatment of esophageal varices [3]. Although balloon-occluded retrograde transvenous obliteration (BRTO) is a new interventional modality for gastric fundic varices [4], a definitive treatment for bleeding ileal varices has not been established. Here we present a case of ruptured ileal varices controlled successfully using B-RTO.

\section{Case Report}

A 55-year-old man with hepatitis B virus antigen-positive liver cirrhosis was admitted to our hospital in October 2007 with anal bleeding. At 36 years of age, he underwent an operation of the ileocecum to remove a benign colonic tumor. At 46 year of age (in 1998), he first received EIS for treatment of esophageal varices and then underwent EIS in 1999 and 2003 for recurrent esophageal varices.

At the time of admission, the patient's blood pressure was 120/62 $\mathrm{mmHg}$, pulse 98 beats/min and regular, and body temperature $36.5^{\circ} \mathrm{C}$. He had anemic conjunctivae, but there was no scleral icterus. The abdomen was soft and flat, there were no obvious abdominal masses. Bleeding was massive and recurrent, and blood transfusions were required. The fibergastroscopic examination on admission revealed small, red color-negative esophageal varices. Laboratory findings were: red blood cell count $209 \times 10^{4} / \mathrm{mm}^{3}$ (normal:353 $\left.466 \times 10^{4} / \mathrm{mm}^{3}\right)$, hemoglobin $5.6 \mathrm{~g} / \mathrm{dL}(10.6-14.4 \mathrm{~g} / \mathrm{dL})$, white blood cell count $6900 / \mathrm{mm}^{3}\left(3000-7800 / \mathrm{mm}^{3}\right)$, platelet count $13.2 \times 10^{4} / \mathrm{mm}^{3}\left(13.8-30.9 \times 10^{4} / \mathrm{mm}^{3}\right)$, serum albumin $2.6 \mathrm{~g} / \mathrm{mL}(4.0-5.2 \mathrm{~g} / \mathrm{mL})$, total bilirubin $0.6 \mathrm{mg} /$ $\mathrm{mL}(0.2-1.2 \mathrm{mg} / \mathrm{mL})$, glutamic oxaliacetic transaminase 14 IU/L ( 8 - $38 \mathrm{IU} / \mathrm{L}$ ), glutamic pyruvic transaminase $18 \mathrm{IU} / \mathrm{L}$ (4 - $44 \mathrm{IU} / \mathrm{L})$, alkaline phosphatase $184 \mathrm{IU} / \mathrm{L}$ (104 - 338 IU/L), blood urea nitrogen $22.9 \mathrm{mg} / \mathrm{dL}(7.0-24.0 \mathrm{mg} / \mathrm{dL})$, and creatine $0.9 \mathrm{mg} / \mathrm{dL}(0.4-0.9 \mathrm{mg} / \mathrm{dL})$. Prothrombin time was $54 \%(90-140 \%)$ and serological assays for markers of hepatitis B viruses were positive. All test results for tumor markers were within the normal range.

Although colonoscopy revealed blood retention in the 


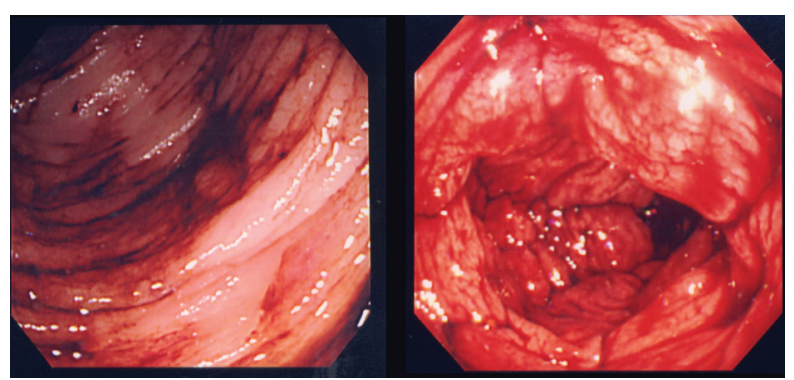

Figure 1. Colonoscopy revealed blood retention in the entire colon, but no bleeding lesion was detected.

entire colon, no bleeding lesions were found (Fig. 1). Because computed tomography (CT) images of vessels in the ileum showed connection to vessels in the right testicular vein (Fig. 2), we suspected ileal varices to be the most probable cause of bleeding. We immediately performed double balloon enteroscopy, but failed to find any site of bleeding owing to the difficulty of fiberscope insertion with sever adhesion. Subsequent interventional radiology involving retrograde transvenous venography using balloon catheter from right subclavian vein revealed ileal varices communicating with the right testicular vein (efferent vein) (Fig. 3a). Angiography revealed that the superior mesenteric vein branch was the afferent vein for the ileal varices.

We performed B-RTO via the efferent vein of the varices. Because of the insufficient varicealography of ileal varices caused by rapid washout of the contrast medium, we performed microcoil embolization using 0.014-inch steel coils for the distal right testicular vein and injected $18 \mathrm{ml}$ of $5 \%$ ethanolamine oleate (EO) containing iopamidol (Fig. 3b). There were no post-operative complications. After B-RTO, venography on the next day could not distinguish the ileal varices or the afferent vein (Fig. 4), and ileal vessel images before B-RTO disappeared after the treatment under CT (Fig. 5). One year after treatment, the patient had experienced no further bleeding.

\section{Discussion}

Portal hypertension can involve either reopening of collapsed embryonic channels or a reversed in flow within existing adult veins [5]. Whereas esophagogastric varices are the most common complication in patients with portal hypertension, ectopic varices defined by large portosystemic venous collaterals occurring anywhere in gastrointestinal tract except in the esophagogastric region are less common and account for between $1 \%$ and $5 \%$ of all variceal bleeding $[6,7]$. Several cases of bleeding ileal varices have been reported [8-16].

Ectopic varices have been reported to occur at numerous sites, including $18 \%$ in the jejunum or ileum, $17 \%$ in the duodenum, $14 \%$ in the colon, $8 \%$ in the rectum, and $9 \%$ in the peritoneum [1]. Most bleeding jejunal and ileal varices, generally detected previous intra-abdominal surgery, are serious due to the difficulty of early diagnosis. In our case, the patient's risk factors included portal hypertension due to liver cirrhosis, EIS for esophageal varices, and previous surgery. Collaterals formation within adhesions from a previous surgery is the usual mechanism for the development of ectopic varices [1]. Adhesions tend to bring the parietal surface of the viscera in contact with the abdominal wall, and portal hypertension results in the formation of varices below intestinal mucosa. Double balloon enteroscopy has gained worldwide acceptance as an endoscopic technique that can be used safely and effectively to provide complete examination of the small bowel, offer therapeutic intervention, and favorably affect clinical outcomes [17-19]. In this case, we immediately performed double balloon enteroscopy to find any site of bleeding, but failed to diagnose owing to the difficulty of fiberscope insertion with sever adhesion.

Surgical approaches such as segmental resection and ligation generally control bleeding from ileal varices successfully $[12,13,20,21]$. In patients with poor condition, interventional radiologic treatment such as insertion of a transjugular intrahepatic portosystemic shunt (TIPS) for ileal
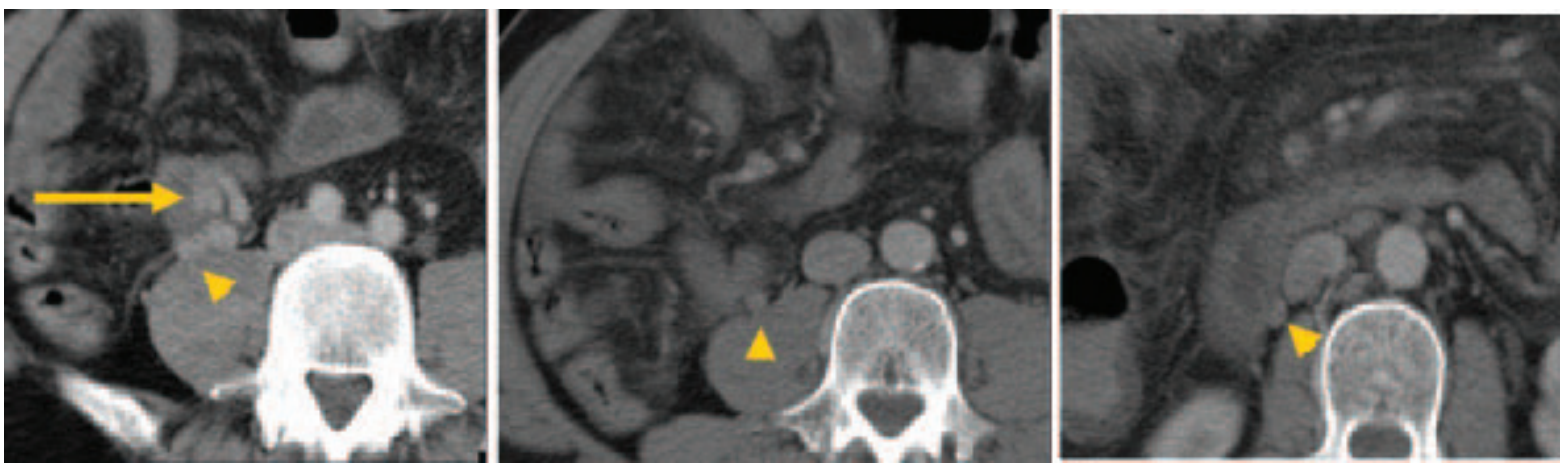

Figure 2. Computed tomography images of a vessel in the ileum (arrow) and its connection to the right testicular vein (arrowhead). 


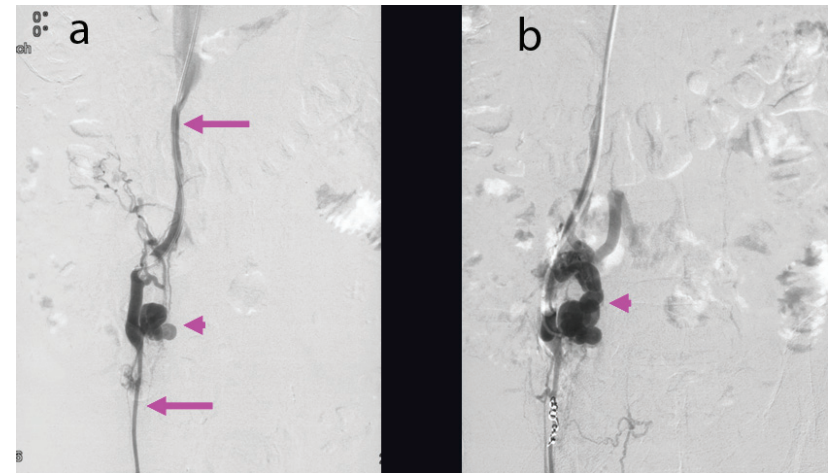

Figure 3. (a) lleal varices (arrowhead) communicating with the right testicular vein (arrow) were found using retrograde transvenous venography. (b) Balloon occluded retrograde transvenous obliteration for ileal varices (arrowhead) was performed via the efferent vein of the varices.

varices have been performed as a non-operative treatment option $[7,14,16]$. Although TIPS is a relatively safe and effective means of decompressing the portal pressure, it may not prove effective in patients with severe liver atrophy or complications such as encephalopathy and cerebral embolization. Because B-RTO can obliterate not only varices but also the afferent veins and efferent veins, it is practical for treating ileal varices [22], as described here. In the future, interventional radiologic treatments such as B-RTO may also be applied as therapy for patients in poor condition.

In summary, ileal varices should be considered in patients that have undergone previous surgery and display lower gastrointestinal bleeding and portal hypertension as well as endoscopic findings that do not reveal any bleeding point.

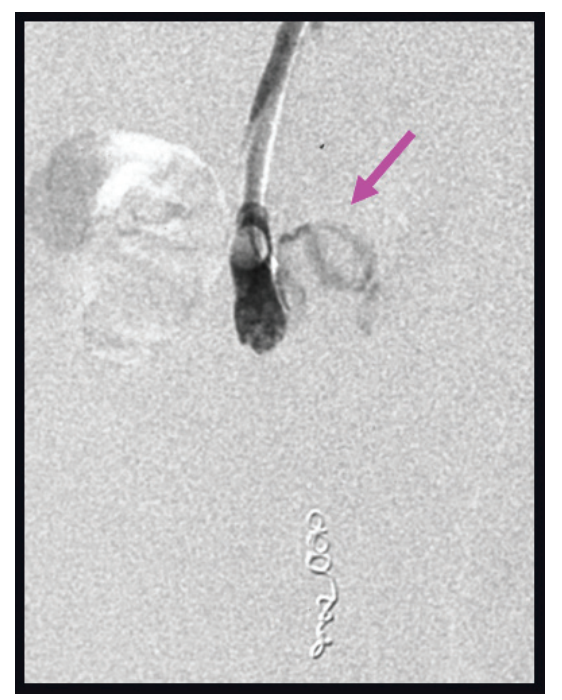

Figure 4. Following balloon occluded retrograde transvenous obliteration, both ileal varices (arrow) and the afferent vein were not visible by venography the next day.

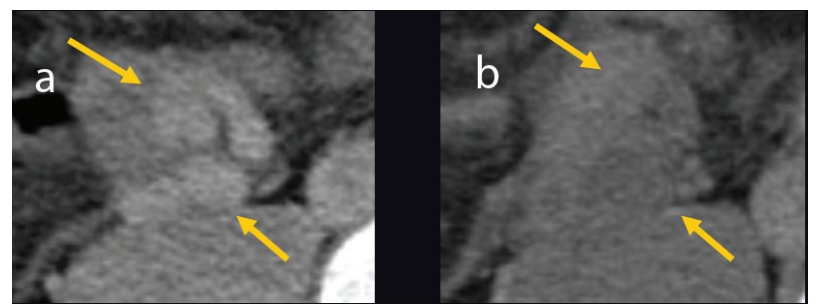

Figure 5. (a) Computed tomography image of ileal vessels before balloon occluded retrograde transvenous obliteration. (b) The ileal vessels are no longer visible following balloon occluded retrograde transvenous obliteration.

\section{Acknowledgements}

The authors declare no commercial associations or conflict of interests related to this article.

\section{References}

1. Lebrec D, Benhamou JP. Ectopic varices in portal hypertension. Clin Gastroenterol 1985;14:105-121.

2. Prophylactic sclerotherapy for esophageal varices in men with alcoholic liver disease. A randomized, singleblind, multicenter clinical trial. The Veterans Affairs Cooperative Variceal Sclerotherapy Group. N Engl J Med 1991;324:1779-1784.

3. Goff JS, Reveille RM, Van Stiegmann G. Endoscopic sclerotherapy versus endoscopic variceal ligation: esophageal symptoms, complications, and motility. Am J Gastroenterol 1988;83:1240-1244.

4. Kanagawa H, Mima S, Kouyama H, Gotoh K, Uchida $\mathrm{T}$, Okuda K. Treatment of gastric fundal varices by balloon-occluded retrograde transvenous obliteration. J Gastroenterol Hepatol 1996;11:51-58.

5. Walsh G, Williams MP. Case report: giant pararectal varices--computed tomographic appearances. $\mathrm{Br} \mathrm{J}$ Radiol 1995;68:203-204.

6. Kinkhabwala M, Mousavi A, Iyer S, Adamsons R. Bleeding ileal varicosity demonstrated by transhepatic portography. AJR Am J Roentgenol 1977;129:514-516.

7. Norton ID, Andrews JC, Kamath PS. Management of ectopic varices. Hepatology 1998;28:1154-1158.

8. Falchuk KR, Aiello MR, Trey C, Costello P. Recurrent gastrointestinal bleeding from ileal varices associated with intraabdominal adhesions: case report and review of the literature. Am J Gastroenterol 1982;77:859-860.

9. Arst HF, Reynolds JD. Acute ileal variceal hemorrhage secondary to esophageal sclerotherapy. J Clin Gastroenterol 1986;8:603-604.

10. Hojhus JH, Pedersen SA. Cirrhosis and bleeding ileal varices without previous intraabdominal surgery. A case 
report. Acta Chir Scand 1986;152:479-480.

11. Lewis P, Warren BF, Bartolo DC. Massive gastrointestinal haemorrhage due to ileal varices. Br J Surg 1990;77:1277-1278.

12. Ohtani T, Kajiwara E, Suzuki N, Kawasaki A, Sadoshima S, Sakata H, Sasaguri Y, et al. Ileal varices associated with recurrent bleeding in a patient with liver cirrhosis. J Gastroenterol 1999;34:264-268.

13. Kobayashi K, Yamaguchi J, Mizoe A, Isomoto I, Koshiishi T, Izawa K, Kanematsu T. Successful treatment of bleeding due to ileal varices in a patient with hepatocellular carcinoma. Eur J Gastroenterol Hepatol 2001;13:63-66.

14. Guth E, Katz MD, Hanks SE, Teitelbaum GP, Ralls P, Korula J. Recurrent bleeding from ileal varices treated by transjugular intrahepatic portosystemic shunt: value of Doppler ultrasonography in diagnosis and follow-up. J Ultrasound Med 1996;15:67-69.

15. Varanasi RV, Fleisher AS, Darwin PE, King CE, Haluszka O. Colonoscopic sclerotherapy of ileal varices. Gastrointest Endosc 2000;52:109-111.

16. Lopez-Benitez R, Seidensticker P, Richter GM, Stampfl U, Hallscheidt P. [Case report: massive lower intestinal bleeding from ileal varices: treatment with transjugular intrahepatic portosystemic shunt (TIPSS)]. Radiologe 2007;47:407-410.
17. May A, Nachbar L, Ell C. Double-balloon enteroscopy (push-and-pull enteroscopy) of the small bowel: feasibility and diagnostic and therapeutic yield in patients with suspected small bowel disease. Gastrointest Endosc 2005;62:62-70.

18. Cazzato IA, Cammarota G, Nista EC, Cesaro P, Sparano L, Bonomo V, Gasbarrini GB, et al. Diagnostic and therapeutic impact of double-balloon enteroscopy (DBE) in a series of 100 patients with suspected small bowel diseases. Dig Liver Dis 2007;39:483-487.

19. Upchurch BR, Vargo JJ. Small bowel enteroscopy. Rev Gastroenterol Disord 2008;8:169-177.

20. Ueda J, Yoshida H, Mamada Y, Taniai N, Mizuguchi Y, Shimizu T, Matsumoto S, et al. Successful emergency enterectomy for bleeding ileal varices in a patient with liver cirrhosis. J Nippon Med Sch 2006;73:221-225.

21. Mashimo M, Hara J, Nitta A, Oohira M, Yamaguchi S, Yamada S, Tanaka H, et al. [A case of ruptured ileal varices associated with alcoholic liver cirrhosis]. Nippon Shokakibyo Gakkai Zasshi 2007;104:561-567.

22. Haruta I, Isobe Y, Ueno E, Toda J, Mitsunaga A, Noguchi S, Kimura T, et al. Balloon-occluded retrograde transvenous obliteration (BRTO), a promising nonsurgical therapy for ectopic varices: a case report of successful treatment of duodenal varices by BRTO. Am J Gastroenterol 1996;91:2594-2597. 